\title{
PROFESSOR SIR DEREK H. R. BARTON AND HETEROCYCLES
}

\author{
Takayuki Shioiri \\ Faculty of Pharmaceutical Sciences, Nagoya City University \\ Tanabe-dori, Mizuho-ku, Nagoya 467, Japan
}

It is my great honor and privilege to introduce scientific contributions by Professor Sir Derek H.R. Barton in this special issue of "Heterocycles" for the celebration of his 70th birthday. As one of Bartonians in Japan, 1 would like to express my sincere congratulations to Professor Barton: Happy Birthdayl

One of the factors which define the importance of a chemist or the greatness of a chemist will be the impact that the man has made on chemistry. Quite a lot of chemical works have become possible as a result of Professor Barton's works. There are many concepts which he has established first. Nobody would object that chemistry today would be quite different without his contributions in a number of areas. Of course, one of the most notable achievements done by the Giant is the establishment of the concept of Conformational Analysis, by which he was awarded the Nobel prize for chemistry in $1969 .^{1}$ He has made a number of outstanding contributions especially on the natural product chemistry involving structure determination, biosynthesis, total synthesis, photochemistry, and so on. In fact, most of his major contributions stem from his interests in natural products, and the resolution of their problems has an impact on the whole of chemistry. His recent interests are mainly directed to the exploitation of "New Methods and Reagents in Organic Synthesis," by which he might be awarded the Nobel prize again.

His ideas, motives, and personal attitudes toward chemistry as well as his footprints in chemistry until 1972 are quite clear if one reads "To jump the gap - an interview with Professor Sir Derek Barton."2 In this article, I do not intend to go into all of his contributions in chemistry since they are too enormous, but rather confine the topics mainly to his contributions in "Heterocycles" which are still too enormous for me to summarize.

The first paper ${ }^{3}$ by Barton is concerned with the volatile excreta from the flour beetle (Tribolium castaneum). He proved them to be ethylbenzoquinone contaminated with some ptoluquinone. This will be the first paper on the structure elucidation of the volatile excreta from insects. After this work, he carried out excellent fundamental works on the catalytic effect in the 
pyrolysis of chlorinated hydrocarbons. Along with this work, he had an interest in the chemistry of steroids and triterpenoids, and has done a large body of outstanding structural works on them. Noteworthy is the application of the method of molecular rotation differences to steroids and triterpenoids for the determination of their configurations. These studies and three dimentional considerations on reactivities of steroids have culminated in the idea of conformational analysis and led him to write the historical paper of 4 pages in 1950.4

In addition to the structural works on steroids and terpenoids, he clarified the complex structure of limonin, 5 the bitter principle of citrus fruits, in collaboration with X-ray crystallographers. During the course of this work, he found a simple hydroxylation procedure which, after some modification, has become an industrial process in the synthesis of certain adrenocortical hormones. However, the structural work on limonin convinced him ${ }^{2}$ that the structural problems are in most cases much more easily solved by $\mathrm{X}$-ray crystallography than they are by organic chemistry.

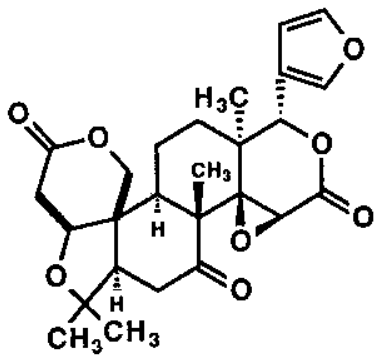

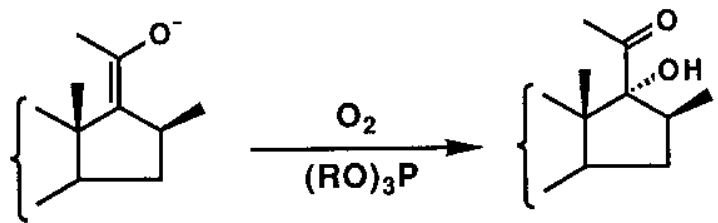

Limonin

One of the most notable synthetic works in his Birkbeck periods (1950-1955) is the extremely short step synthesis of usnic acid, 6 the main lichen constituent, based on phenolic radical coupling.<smiles>CC(=O)c1c(O)cc(O)c(C)c1O</smiles>

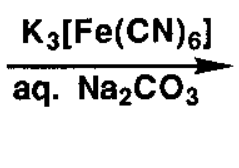<smiles>CC(=O)C1=C(O)C2(C)c3c(O)c(C)c(O)c(C(C)=O)c3OC2(O)CC1=O</smiles><smiles>CC(C)C(=O)OCC(=O)OS(=O)(=O)O</smiles><smiles>CC(=O)C1=C(O)C2(C)C(=CC1=O)Oc1c(C(C)=O)c(O)c(C)c(O)c12</smiles>

Usnic acid 
This success was followed by not only his considerable amount of works on the biosynthesis and synthesis of many alkaloids based on phenolic radical coupling, but also the others' similarly patterned biogenetic type synthesis of complex natural products. His idea about biosynthesis is based on the assumption that enzymatically - induced reactions follow the same mechanistic principles as ordinary organic reactions. After a number of predictions with emphasis on the role of phenol coupling in nature, 7 he has done a number of the biosynthetic works on alkaloids. ${ }^{8,9}$ He has made clear the correct biosynthetic pathway of morphine from (-)reticuline, which undergoes phenolic coupling to give salutaridine, then transforms to morphine via thebaine in nature. Furthermore, he has completed a long sought synthesis of morphine alkaloids patterned after the biosynthetic pathway by means of phenolic radical coupling of reticuline as a key step. Analogous phenolic oxidation of $\mathrm{N}$-methylcoclaurine afforded glaziovine, one of proaporphine (dienone) alkaloids. Sinomenine having an enantiomeric-type relationship with the morphine alkaloids was proved by him to be biosynthesized from (+)-reticuline, which corrected Robinson's original proposal on the biosynthesis of sinomenine.<smiles>COc1ccc(C[C@@H]2CN(C)[C@H]2c2cc(O)c(OC)cc2C)cc1O</smiles>

(-)-Reticuline<smiles>CN[C@@H]1C[C@@H]2Cc3ccc(OC)c4c3[C@]2(CC=COC)CCN41</smiles>

Thebaine

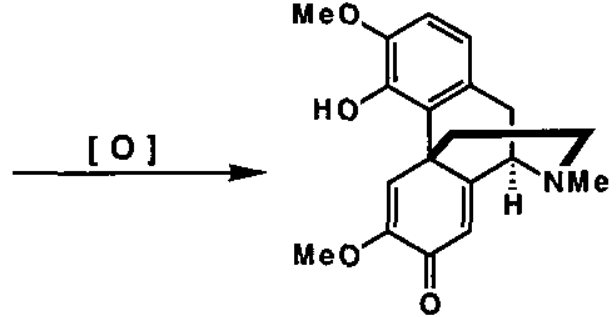

Salutaridine

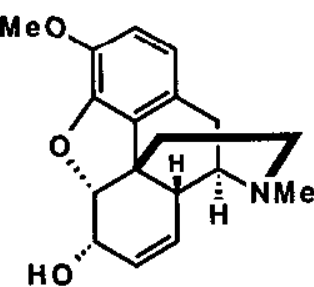

Morphine<smiles></smiles>

Glaziovine<smiles>CCC12CCC(C1)[C@@H](NC)Cc1ccc(OC)c(O)c12</smiles>

Sinomenine

Biosynthesis of aromatic Erythrina alkaloids such as erythraline was also proved by him to involve phenolic coupling, during which works he could settle the structures of some of Erythrina alkaloids. 


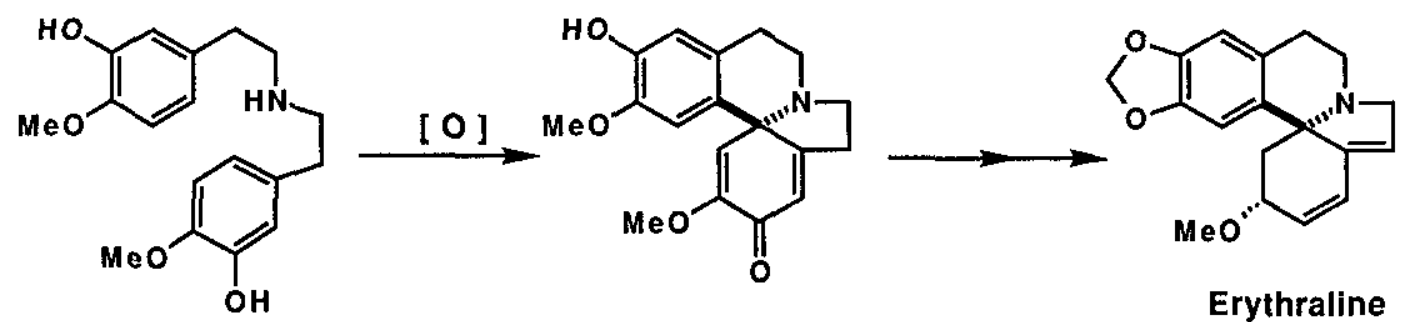

His another pioneering achievement using phenolic oxidation is the short step synthesis of galanthamine, one of the representatives of the Amaryllidaceae alkaloids. ${ }^{10}$

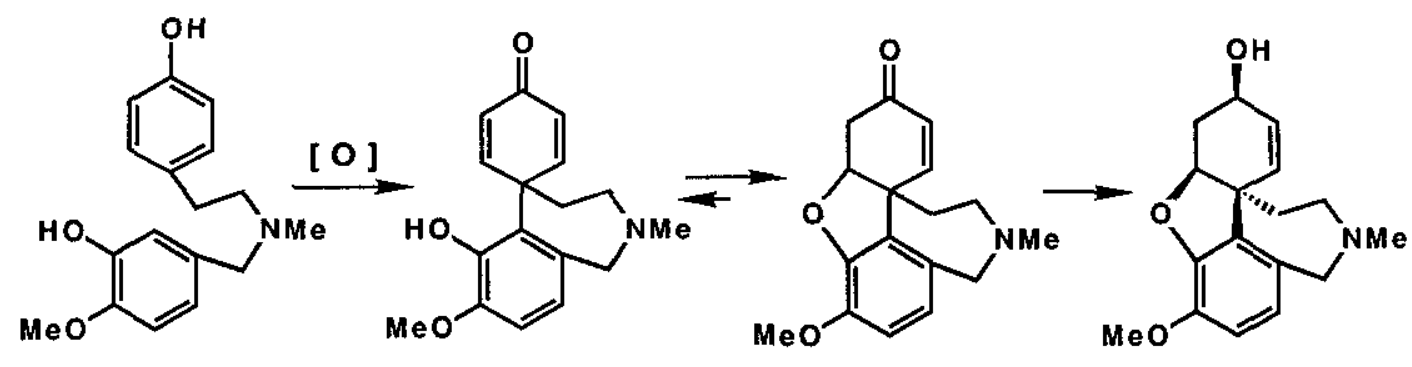

\section{Galanthamine}

The first target of Barton's photochemical works is santonin, a well-known anthelmintic, whose photochemistry revealed a remarkably complex and interesting series of molecular acrobatics of a kind which had never been seen before in organic chemistry.2,11 This together with the other groups' works made a new light to old organic photochemistry.<smiles>CC[C@H]1OC(=O)[C@H](C)[C@@H]2CC[C@@]3(C)C=CC(=O)C=C3C(C)=C21</smiles>

$\alpha$-Santonin<smiles>CC(C)C(=O)O</smiles>

$\mathrm{ACOH}$<smiles>CC1=C2C(=O)C(=O)C[C@@H]2[C@@](C)(O)CC[C@H]1C</smiles>

Activation of the inert carbon was another photochemical target, which led him to invent a new reaction called after his name, Barton reaction. 12 The Barton reaction or nitrite photolysis is quite useful especially for the activation of the angular methyl groups in steroids, providing an excellent synthetic route to 18- and 19-substituted steroids. One of its most spectacular application is the facile conversion of corticosterone acetate to aldosterone acetate. Aldosterone, the important adrenocortical hormone, was produced in $40-50 \mathrm{~g}$ quantities according to his method at a time when the total world supply was only a few $\mathrm{mgl} 2,13$ 

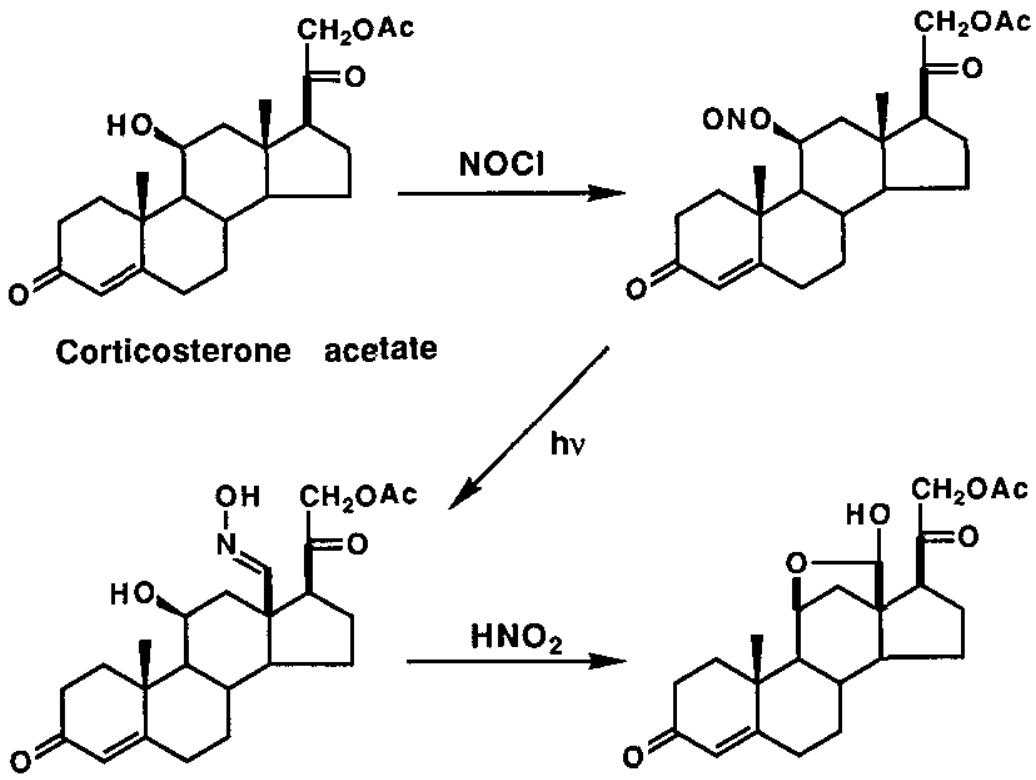

Aldosterone acetate

Partial synthesis of conessine, a representative of Kurchi alkaloids, was also achieved by him using the Barton reaction to form its ring $E .^{14}$

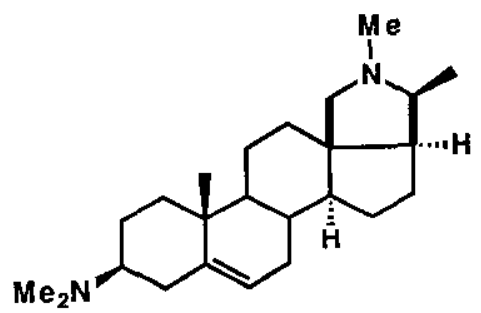

Conessine

Two well-known antibiotics, tetracycline and penicillin, have also been Barton's concerns. Towards the total synthesis of tetracycline, interesting chemistries have been developed, 15 among which the acid catalyzed photocyclization will be noteworthy.

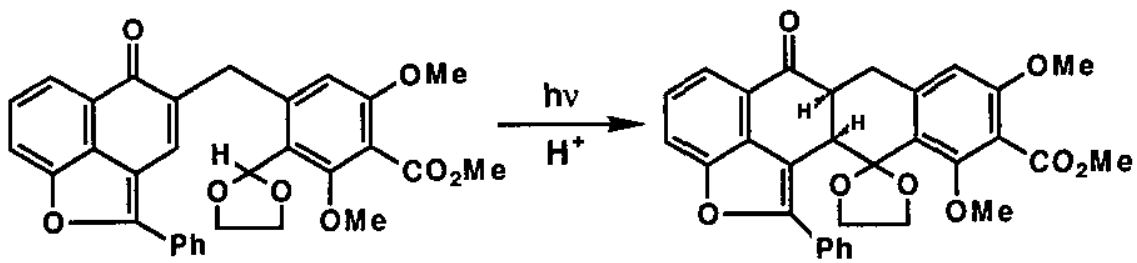


Furthermore, requirement for the introduction of a hydroxyl group at the ortho position of the phenolic group in the tetracycline synthesis led him to exploit benzeneseleninic anhydride as a useful oxidizing agent. ${ }^{16}$ One of recent examples of the use of this oxidant is the aromatization of indolines to indoles, which was applied to the total synthesis of ergot alkaloids by co-operation with Ninomiya's group. 17<smiles>CN1C[C@H](CO)C=C2c3cccc4c3[C@@H](CN4)C[C@H]21</smiles><smiles>CN1C[C@H](CO)C=C2c3ccc(C4CCCCC4)c4[nH]cc(c34)C[C@H]21</smiles>

Lysergol

Transformation of penicillin to cephalosporin through 2,3-sigmatropic rearrangement of penicillin sulfoxide has been studied in detail. ${ }^{18}$ During this work, he developed a new protecting group for carboxylic acids which can be removed under mild oxidative conditions. Furthermore, simple procedures for the conversion of penicillin to simple B-lactams have also been developed.
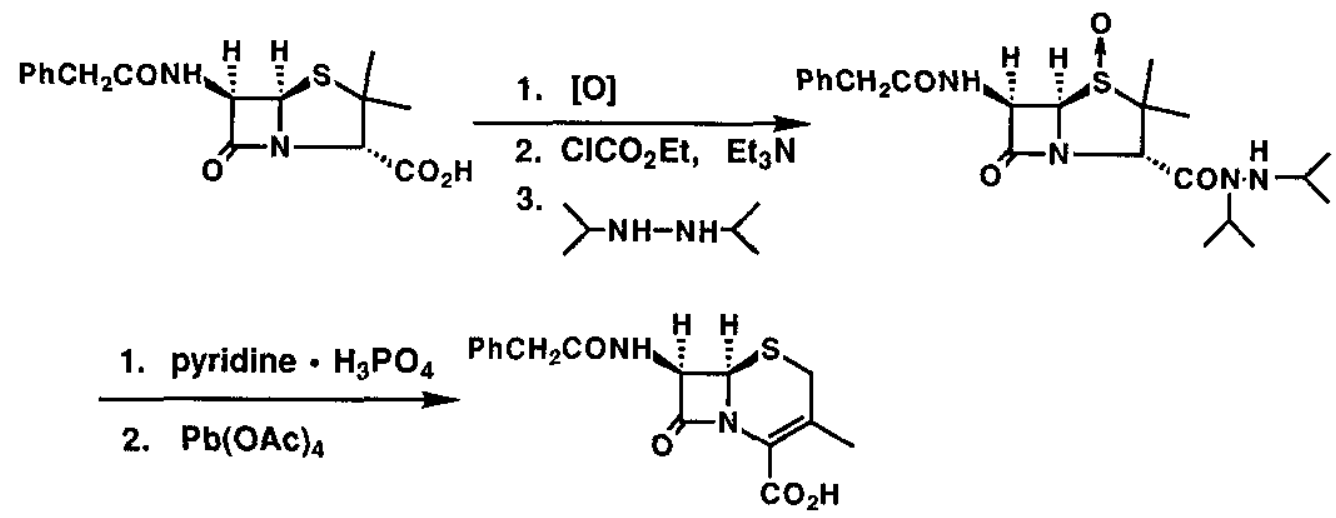

In addition to the studies on biosynthesis of alkaloids, biosynthesis of steroids and triterpenoids, Barton's old friends, has also been investigated. During these studies, a new protective method for 1,3-dienes using 4-phenyl-1,2,4-triazoline-3,5-dione (PTAD), a powerful dienophile, ${ }^{19}$ and its analogs was invented. 20 Deprotection is easily carried out by reductive ${ }^{19}$ or hydrolytic $^{20}$ method. This convenient protective method is now used in pharmaceutical industry to produce active vitamin $\mathrm{D}$. 


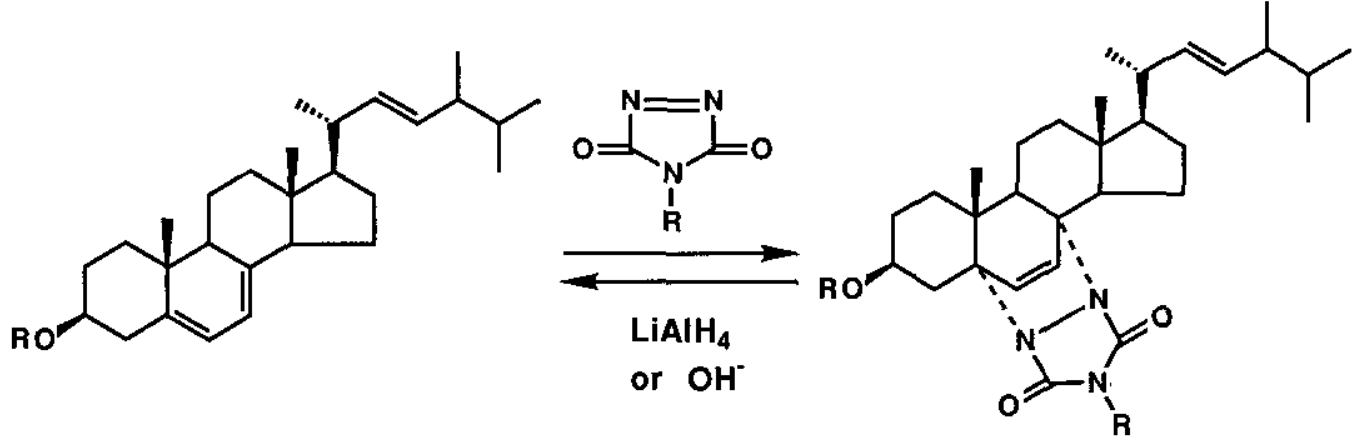

Replacement of hydrogen with fluorine sometimes profoundly influences the pharmacological properties of organic molecules. For the selective fluorination, Barton developed hypofluorites, especially trifluoromethyl hypofluorite $\left\langle\mathrm{CF}_{3} \mathrm{OF}\right\rangle$, as reagents with unusual electrophilic character. 21 Noteworthy is the easy preparation of 5-fluorouracil, a well-known anticancer drug, by fluorination of uracil with $\mathrm{CF}_{3} \mathrm{OF}$, though awkward elemental fluorine was also found to be applicable to the same reaction.<smiles></smiles>

According to Barton, there are three ways of inventing a reaction or a reagent: viz . by conception, by misconception or by accident. Most of the known useful reactions were discovered by accident. However, the idea that hypofluorites would show electrophilic fluorine behavior is a conception. 21

Almost these ten years he has been developing the otherwise uncontroltable radical chain reactions to a well-controlled and useful method in preparative organic chemistry. $22 \mathrm{He}$ summarizes the advantages of radical chain reactions over ionic reactions as follows:

(1) Proceed under neutral conditions.

(2) Are less subject to interference from: -
(A) steric effects
(B) polar effects
(C) competing carbocationic rearrangement or carbanionic elimination reactions. 
The first radical chain reaction he has invented is the deoxygenation of hindered secondary hydroxyl groups in carbohydrates, which is achieved by the reduction of a thiocarbonyl ester, xanthate ester or thiocarbonylimidazolide with tributyltin hydride or other metal hydride reagents. The exceptional tolerance of other functional groups and absence of B-elimination are observed in the deoxygenation of the complex aminoglycoside antibiotics.

Target: $\quad$ Deoxygenation : $\mathrm{ROH} \longrightarrow \mathrm{RH}$

Conception: Reaction course ( reaction mechanism)

Proof: Successful example
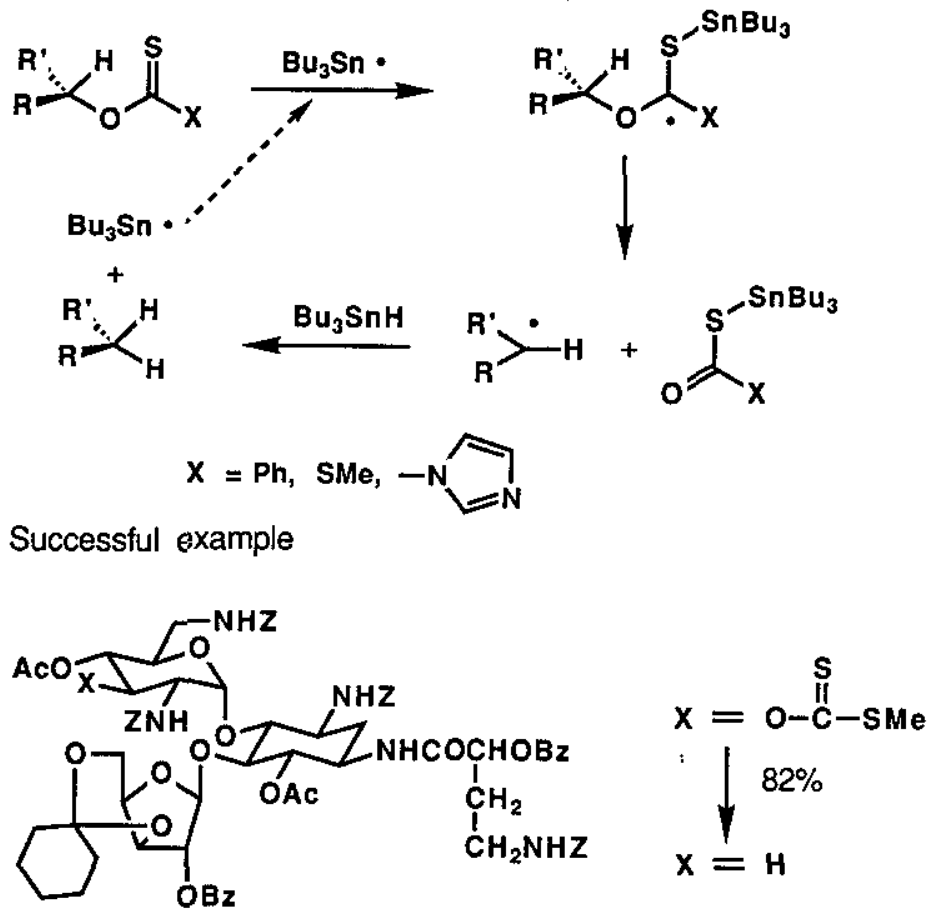

In a conceptually similar approach, he developed an efficient radical deamination method based on the reaction of isocyanides with tributyistannane. The corresponding reduction of isothiocyanides and of isoselenocyanates also affords the deaminated products. Since the order of reactivity is tertiary > secondary > primary isocyanide, selective deamination is possible by simple adjustment of the reaction temperature. By this procedure, a number of deaminated neamine derivatives were prepared for the study of structure-activity relationships.

His achievements on the radical decarboxylation of carboxylic acids opened a new chapter in radical chemistry. After several conceptually interesting approaches, the definitive solution was made by use of esters derived from $\mathrm{N}$-hydroxy-2-thiopyridone. These esters can be easily 
prepared from the corresponding acids, and undergo the decarboxylation with tributylstannane or preferably with tert-butyl mercaptan.

Target: $\quad$ Deamination: $\mathrm{RNH}_{2} \longrightarrow \mathrm{RH}$

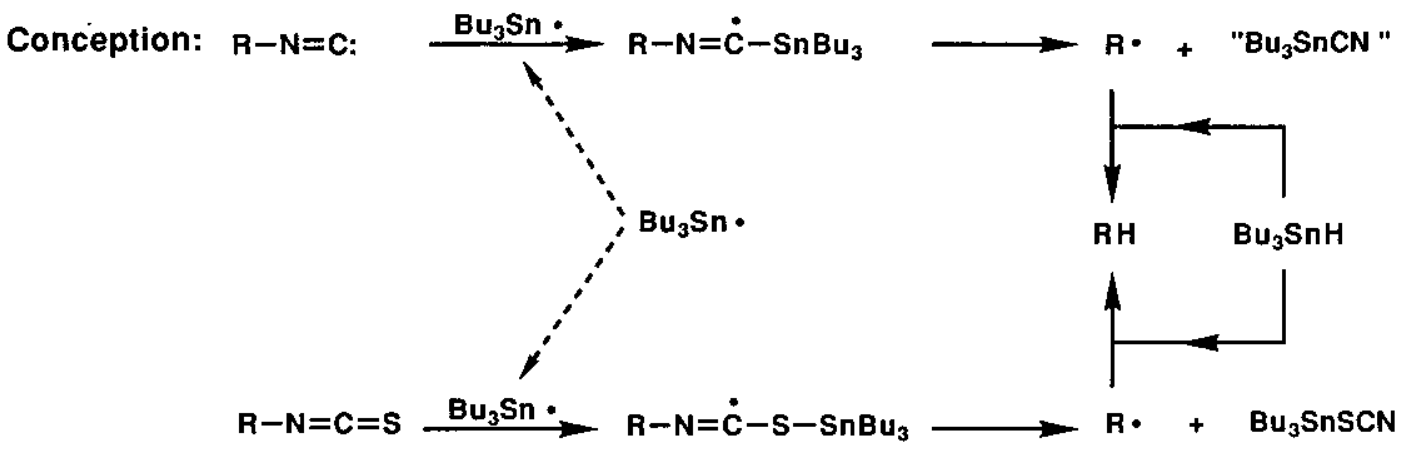

Proof:

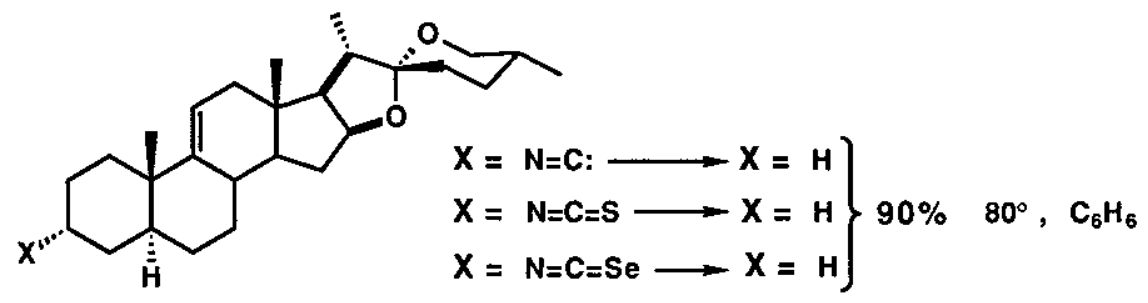

Target: $\quad$ Decarboxylation : $\mathrm{RCOOH} \longrightarrow \mathrm{RH}$

Conception:

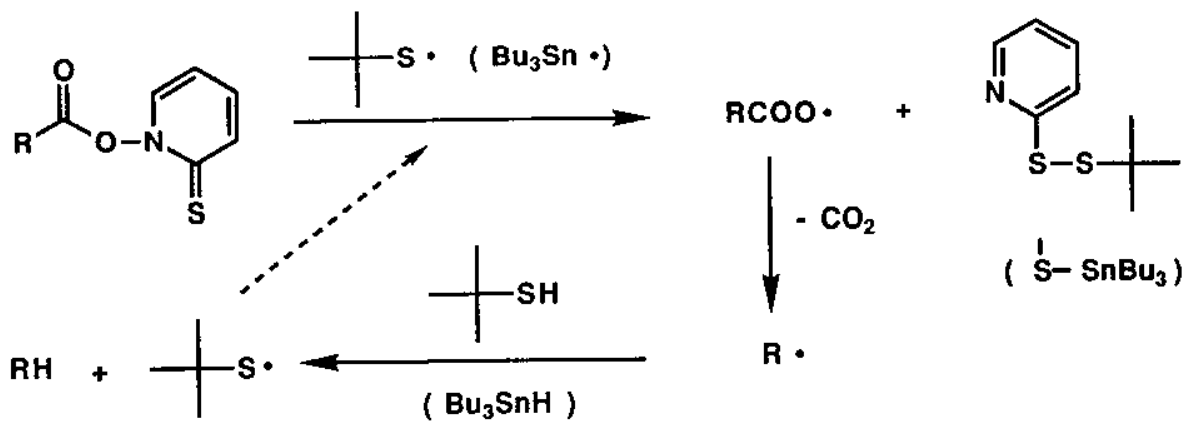

$\left(\mathrm{Bu}_{3} \mathrm{Sn} \cdot\right)$

A similar decarboxylative process produces chlorides, bromides, and iodides when the reaction is carried out in the presence of carbon tetrachloride, bromotrichloromethane, and iodoform, respectively. This new method is far superior to the classical Hunsdiecker reaction. Sulfides, selenides, and tellurides can be prepared similarly. 


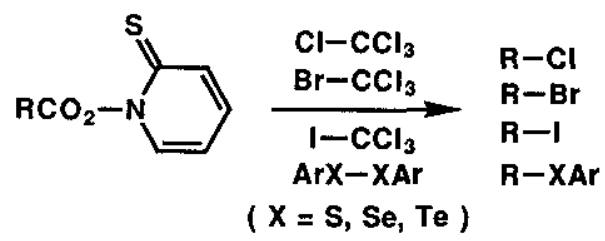

The chemistry based on the trapping of the carbon radical from $\mathrm{N}$-hydroxy-2-thiopyridone esters has expanded to the formation of alcohols, aldehydes or ketones and the formation of carbon-carbon bonds. Radical deoxygenation of tertiary alcohols has also been achieved by use of $\mathrm{N}$-hydroxy-2-thiopyridone in the form of its hemi-ester of oxalic acid. Interestingly, creation of the formation of a quaternary center has been attained when the reaction is carried out in the presence of acrylate esters.
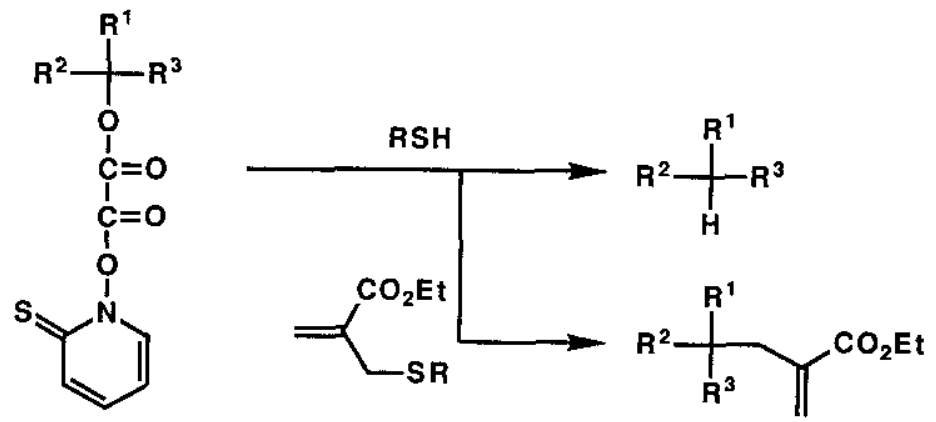

Furthermore, an excellent method for the conversion of carboxylic acids to alcohols was devised by stirring a mixture of tris(phenylthio)antimony and the esters of $\mathrm{N}$-hydroxy-2-thiopyridone under air at room temperature.

Photochemical operations has opened another synthetic utility of the esters of N-hydroxy-2thiopyridone, leading to the radical decarboxylative addition onto protonated heteroaromatics such as purine bases 23 and the radical decarboxylative cyclization. 24<smiles>O=C(Nc1ncnc2[nH]cnc12)c1ccccc1</smiles><smiles>[R]C(=O)On1ccccc1=S</smiles><smiles>[R]c1nc(NC(=O)c2ccccc2)c2nc[nH]c2n1</smiles> 


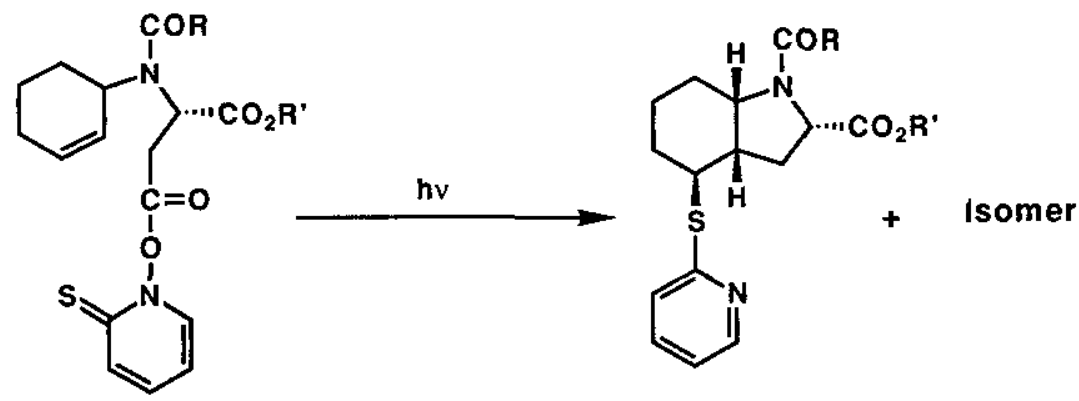

Apart from radical chain reactions, he has developed a new ionic process for the synthesis of pyrroles under mild reaction conditions. 25

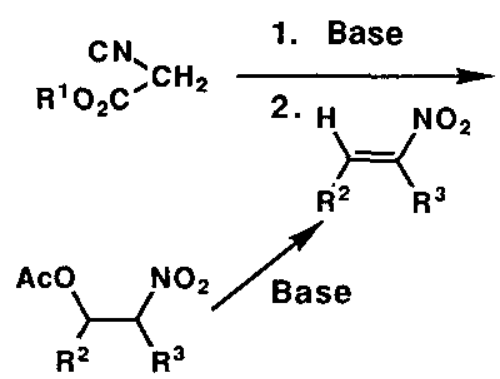<smiles>[R7]OC(=O)c1[nH]cc([R7])c1[R]</smiles>

Pyrroles have also been formed by intramolecular cyclization of 1,4-nitroketones by combination of tributylphosphine and diphenyl disulfide, a self-drying reagent. 26<smiles>[R7]C(=O)C([R])C([R7])C([R7])[N+](=O)[O-]</smiles>

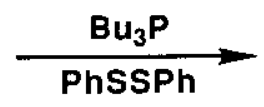<smiles>[R7]c1[nH]c([R7])c([R])c1[R]</smiles>

Utilizing the heterocycles as an aid in synthesis, Barton developed an efficient and short degradation of the cholic acid side chain, useful for the synthesis of corticosteroids. 27 Boric acid mediated condensation of aliphatic carboxylic acids with 2-amino-2-methylpropan-1-ol efficiently affords the oxazolines, which undergo dehydrogenation with benzeneseleninic acid or anhydride. In the case of the cholic acid derivative, acylation followed by ozonolysis and saponification furnished the 20-oxopregnane derivative in good yield. 


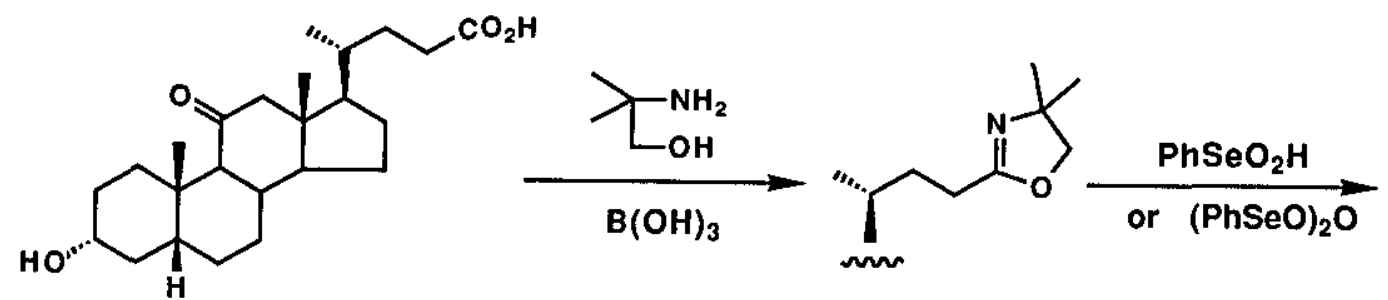

11- Oxolithocholic acid<smiles>CC(C)/C=C/C1=NC(C)(C)CO1</smiles><smiles>CC(C)(C)[C@H](O)[C@H](O)C(=O)Cl</smiles><smiles>CC(=O)[C@H]1CCC2C3CC[C@@H]4C[C@H](O)CC[C@]4(C)[C@H]3C(=O)C[C@@]21C</smiles>

Utilization of metalloids such as tellurium and bismuth in organic synthesis has also been another area in which Barton has developed interesting and useful chemistry. He has proved sodium hydrogen telluride is an interesting reductant for the immonium salts such as the isoquinolinium salts. 28

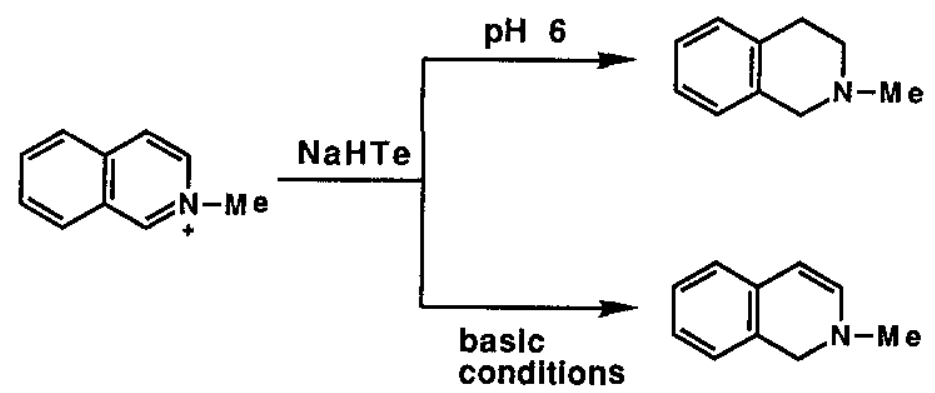

Organobismuth(V) reagents have been found by him 29 to be not only useful oxidants for alcohols, but also effective reagents for arylation on oxygen, carbon, and nitrogen. Mechanistically, these reactions have been proved to proceed via reductive elimination. This useful arylation reaction 30 has been found by accident when the oxidation of quinine to quininone was tried by use of triphenylbismuth carbonate.<smiles>C=CC1CN2CCC1C2[C@H](O)c1ccnc2ccc(OC)cc12</smiles> 
Professor Barton's contributions to chemistry are quite enormous and influential. He has been always creating new and long-lasting fashions in chemistry, and they have contributed not only to the progress of chemistry but also to human welfare.

When 1 met him for the first time at his office of the Imperial College, London, in April 1968, he said to me "How do you do?" with shaking hands. The next words which he said was "Now, let's talk about chemistry"l Yes, his whole life is completely devoted to chemistry. Professor Barton is now working at Texas A \& M University in U. S. A. after his retirement from the Imperial College in London (U. K.) in 1978 and from l'institut de Chimie des Substances Naturelles, C. N. R. S., in Gif-sur-Yvette (France) in 1986. However, I am confident that he would never retire from chemistry! 1 guess he is still working hard in Texas from 8 a.m. 108 p.m. while travelling all over the world with his wife, Christiane, to do numerous invited lectures at various places.

Both Professor and Mrs. Barton are quite healthy. I sincerely wish him a happy and fruitful life with her and the continuation of his research to find out new frontiers of chemistry till the next 21 st century.

ACKNOWLEDGMENTS I sincerely thank Professor Sir Derek H. R. Barton for his sending me reprints of his recent papers for preparing this article. Thanks are also due to Dr. T. Aoyama and Mr. O. Hara for their co-operation.

\section{REFERENCES}

1. D.H.R. Barton, 'Stereochemistry of Organic and Bioorganic Transformations,' ed. by W. Bartmann and K.B. Sharpless, VCH, Weinheim, 1987, pp. 205-219.

2. Chem. in Britain, 1973, 9, 149.

3. P. Alexander and D.H.R. Barton, Biochem. J., 1943, 37, 463.

4. D.H.R. Barton, Experientia, 1950, 6, 316. Actually, this historical paper covers 4.5 pages.

5. D.H.R. Barton, S.K. Pradhan, S. Sternhell, and J.F. Templeton, J. Chem. Soc., 1961, 255.

6. D.H.R. Barton, A.M. Deflorin, and O.E. Edwards, J. Chem. Soc., 1956, 530.

7. D.H.R. Barton and T. Cohen, Festschrift A. Stoll, Birkhauser, Basel, 1957, p. 117.

8. D.H.R. Barton, Pure Appl. Chem., 1964, 9, 35.

9. D.H.R. Barton, Chem. in Britain, 1967, 3, 330.

10. D.H.R. Barton and G.W. Kirby, J. Chem. Soc., 1962, 806.

11. D.H.R. Barton, Helv. Chim. Acta, 1959, 42, 2604.

12. D.H.R. Barton, J.M. Beaton, L.E. Geller, and M.M. Pechet, J. Am. Chem. Soc., 1961, 83, 
4076.

13. D.H.R. Barton and J.M. Beaton, J. Am. Chem. Soc., 1961, 83, 4083.

14. D.H.R. Barton and A.N. Starratt, J. Chem. Soc., 1965, 2444.

15. D.H.R. Barton, Pure Appl. Chem., 1971, 25, 5.

16. D.H.R. Barton and S.V. Ley, 'Further Perspectives in Organic Chemistry,' Elsevier, Amsterdam, 1978, pp. 53-66.

17. I. Ninomiya, C. Hashimoto, T. Kiguchi, D.H.R. Barton, X. Lusinchi, and P. Milliet, Tetrahedron Lett., 1985, 26, 4187.

18. D.H.R. Barton, Pure Appl. Chem., 1973, 33, 1.

19. D.H.R. Barton, T. Shioiri, and D.A. Widdowson, J. Chem. Soc. (C), 1971, 1968.

20. D.H.R. Barton, X. Lusinchi, and J. Sandoval Ramirez, Tetrahedron Lett., 1983, 24, 2995; Idem, Bull. Soc. Chim. France, 1985, 849.

21. D.H.R. Barton, Pure Appl. Chem., 1970, 21, 285; Idem, Pure Appl. Chem., 1977, 49, 1241.

22. D.H.R. Barton and B.W. Motherwell, Pure Appl. Chem., 1981, 53, 15; Idem, Heterocycles, 1984, 21, 1; D.H.R. Barton and S.Z. Zard, Pure Appl. Chem., 1986, 58, 675.

23. D.H.R. Barton, B. Garcia, H. Togo, and S.Z. Zard, Tetrahedron Lett., 1986, 27, 1327; E. Castagnino, S. Corsano, D.H.R. Barton, and S.Z. Zard, Ibid., 1986, 27, 6337.

24. D.H.R. Barton, J. Guihem, Y. Hervé, P. Potier, and J. Thierry, Tetrahedron Lett., 1987, 28, 1413.

25. D.H.R. Barton and S.Z. Zard, J. Chem. Soc., Chem. Commun., 1985, 1098.

26. D.H.R. Barton, W.B. Motherwell, E.S. Simon, and S.Z. Zard, J. Chem. Soc. Perkin Trans. I, 1986, 2243.

27. D.H.R. Barton, W.B. Motherwell, J. Wozniak, and S.Z. Zard, J. Chem. Soc. Perkin Trans. I, 1985, 1865.

28. D.H.R. Barton, A. Fekih, and X. Lusinchi, Tetrahedron Lett., 1985, 26, 3693.

29. D.H.R. Barton and J.-P. Finet, Pure Appl. Chem., 1987, 59, 937.

30. R.A. Abramovich, D.H.R. Barton, and J.-P. Finet, Tetrahedron, 1988, 44, 3039. 